\title{
Technical note: Development of a quantitative PCR method for monitoring strain dynamics during yogurt manufacture
}

\author{
D. M. Miller, E. G. Dudley, and R. F. Roberts ${ }^{1}$ \\ Department of Food Science, The Pennsylvania State University, University Park 16802
}

\begin{abstract}
Yogurt starter cultures may consist of multiple strains of Lactobacillus delbrueckii ssp. bulgaricus (LB) and Streptococcus thermophilus (ST). Conventional plating methods for monitoring LB and ST levels during yogurt manufacture do not allow for quantification of individual strains. The objective of the present work was to develop a quantitative PCR method for quantification of individual strains in a commercial yogurt starter culture. Strain-specific primers were designed for 2 ST strains (ST DGCC7796 and ST DGCC7710), 1 LB strain (DGCC4078), and 1 Lactobacillus delbrueckii ssp. lactis strain (LL; DGCC4550). Primers for the individual ST and LB strains were designed to target unique DNA sequences in clustered regularly interspersed short palindromic repeats. Primers for LL were designed to target a putative mannitol-specific IIbC component of the phosphotransferase system. Following evaluation of primer specificity, standard curves relating cell number to cycle threshold were prepared for each strain individually and in combination in yogurt mix, and no significant differences in the slopes were observed. Strain balance data was collected for yogurt prepared at 41 and $43^{\circ} \mathrm{C}$ to demonstrate the potential application of this method.
\end{abstract}

Key words: starter culture, Streptococcus thermophilus, Lactobacillus delbrueckii, real-time quantitative polymerase chain reaction (qPCR)

\section{Technical Note}

Yogurt starter cultures typically consist of multiple strains of Lactobacillus delbrueckii ssp. bulgaricus (LB) and Streptococcus thermophilus (ST; Auclair and Accolas, 1983). Lactobacillus delbrueckii ssp. bulgaricus and ST strains can differ with regard to optimum growth temperature and the production of acid, aroma, flavor compounds, and exopolysaccharide produced during fermentation (Imhof et al., 1995; Tamime and Rob-

Received February 19, 2012.

Accepted April 15, 2012.

${ }^{1}$ Corresponding author: rfr3@psu.edu inson, 1999; Broadbent et al., 2003). Thus, particular strains are selected for commercial starter cultures so that under a specific set of conditions (e.g., yogurt mix formulation and temperature), the strain balance achieved promotes rapid acidification while producing a product with the desired organoleptic qualities (Chandan and O'Rell, 2006).

At times, it may be necessary or desirable to change the yogurt mix formulation or fermentation conditions, but such modifications can alter the growth profile and balance of individual strains (Radke-Mitchell and Sandine, 1986). Conventional plating methods for following ST and LB levels during yogurt manufacture require 48 to $72 \mathrm{~h}$ and do not allow for enumeration of individual strains because strains of the same species or subspecies are phenotypically very similar (IDF, 1988). In such cases, molecular techniques such as quantitative PCR (qPCR), which can discriminate between individual strains, would improve our understanding of the relationship between strain balance and product quality. The objective of this study was to develop a qPCR method for monitoring individual strains in a commercial starter culture during yogurt manufacture.

Development of a qPCR method for monitoring individual strains is contingent on identification of unique sequences, which can be used as targets for primers. Clustered regularly interspersed short palindromic repeat (CRISPR) sequences, which have been shown to be prevalent in the genomes of lactic acid bacteria including Lactobacillus spp. and Streptococcus spp., have been shown to be highly variable, allowing differentiation at the strain level (Horvath et al., 2008, 2009). The CRISPR sequences consist of alternating repeat sequences, which are short and highly conserved, and spacers, which are highly variable. In ST strains, repeat sequences are typically $36 \mathrm{bp}$ in length, whereas repeats for LB are usually between 28 and $30 \mathrm{bp}$ in length (Horvath et al., 2008, 2009). Repeats are separated by spacers, whose sequences are commonly derived from bacteriophage and other foreign DNA and confer resistance to phage attack (Barrangou et al., 2007). Differences in the number of repeats and spacers as well as the arrangement and sequence of the spacers have been observed in ST strains (Horvath et al., 2008). 
In this study, 2 commercial ST strains (DGCC7796 and 7710), 1 LB strain, (DGCC4078), and 1 Lactobacillus delbrueckii ssp. lactis strain (LL; DGCC4550) were obtained from Danisco USA Inc. (Madison, WI). The ST strains were propagated at $37^{\circ} \mathrm{C}$ in M17 broth with lactose [Becton Dickinson and Co. (BD), Franklin Lakes, NJ]. The LB and LL strains were cultivated in acidified de Man, Rogosa, and Sharpe (MRS) broth $(\mathrm{pH} 5.4 ; \mathrm{BD})$ and incubated at $37^{\circ} \mathrm{C}$ under anaerobic conditions (10\% carbon dioxide, $5 \%$ hydrogen, and $85 \%$ nitrogen). Stock cultures were prepared from overnight cultures by combining equal quantities of broth and $20 \%$ glycerol (wt/vol; Sigma-Aldrich Corp., St. Louis, $\mathrm{MO}$ ) and were stored at $-80^{\circ} \mathrm{C}$.

Primers for the individual ST strains were designed to target CRISPR loci previously identified in these strains (GenBank accession no. EF434468 and EF434469; http://www.ncbi.nlm.nih.gov/genbank/; Table 1; Barrangou et al., 2007). The primer set for LB was designed to target a CRISPR locus based on sequence information provided by the culture supplier. Because a CRISPR sequence was not available for LL, primers were designed to target a sequence in the phosphotransferase system, mannitol-specific IIbC component gene (GenBank accession no. AF496224.1). Primers were designed with Primer-Blast (http://www.ncbi. nlm.nih.gov/tools/primer-blast/index.cgi?LINK_LOC $=$ BlastHome), and primer specificity was evaluated in silico and by conventional PCR. Agarose gel electrophoresis was used to confirm that a single amplicon of the correct size was produced for the target strain and no cross-reaction occurred with each strain-specific primer set and the nontarget strains in that particular starter culture (data not shown).

Quantitative PCR experiments were conducted to identify the optimal annealing temperature and primer concentration for each primer set (data not shown). The optimized qPCR reaction mix consisted of $\mathrm{iQ}$ SYBR Green Super Mix (50 $\mu$ L; Bio-Rad Laboratories Inc., Hercules, CA), primers at a final concentration of $50 \mathrm{n} M$, and nuclease-free water for a final reaction volume of $100 \mu \mathrm{L}$. Aliquots $(25 \mu \mathrm{L})$ of the reaction mix were dispensed in triplicate wells, and qPCR was conducted with an iQ5 real-time PCR detection system (Bio-Rad Laboratories Inc.). Optimized qPCR conditions consisted of $95^{\circ} \mathrm{C}$ for $5 \mathrm{~min}$, followed by 35 cycles of $95^{\circ} \mathrm{C}$ for $30 \mathrm{~s}, 64.6^{\circ} \mathrm{C}$ for $30 \mathrm{~s}$, and $72^{\circ} \mathrm{C}$ for $10 \mathrm{~s}$. Following qPCR, melting curve analysis was conducted at temperatures ranging from 55 to $95^{\circ} \mathrm{C}$, with a $0.5^{\circ} \mathrm{C}$ increase every $30 \mathrm{~s}$. Agarose gel electrophoresis was used to verify that a single reaction product of the expected size was produced, and cross-reaction with other strains in the starter culture was not observed (data not shown).

Standard curves were prepared with individual strains spiked in the yogurt mix. The yogurt mix was prepared by combining 7:1 water and nonfat, dry milk powder in a large stainless steel canister (final concentration $12.5 \%$ milk solids-not-fat). The mix was heated to $200^{\circ} \mathrm{F}\left(93.3^{\circ} \mathrm{C}\right)$ for $45 \mathrm{~min}$ with constant agitation and then cooled and stored at $4^{\circ} \mathrm{C}$.

Aliquots of individual strains grown in M17 with lactose or acidified MRS broth $(45 \mathrm{~mL})$ were transferred to sterile, $50-\mathrm{mL}$ centrifuge tubes and centrifuged for 5 min at $1,250 \times g$ (Beckman GPR centrifuge; Beckman Instruments Inc., Fullerton, CA). The supernatant was discarded and the pelleted cells were resuspended in $0.1 \%$ Polypeptone (BD) to yield cell concentrations of approximately $10^{9} \mathrm{cfu} / \mathrm{mL}$. Serial dilutions were prepared in $0.1 \%$ Polypeptone (BD) and cell concentrations were determined by plating. Serial dilutions of ST strains were plated in duplicate on M17 agar

Table 1. Strain-specific primers for commercial starter culture strains and Lactobacillus farciminis (LF) ATCC $29644^{\mathrm{T}}$

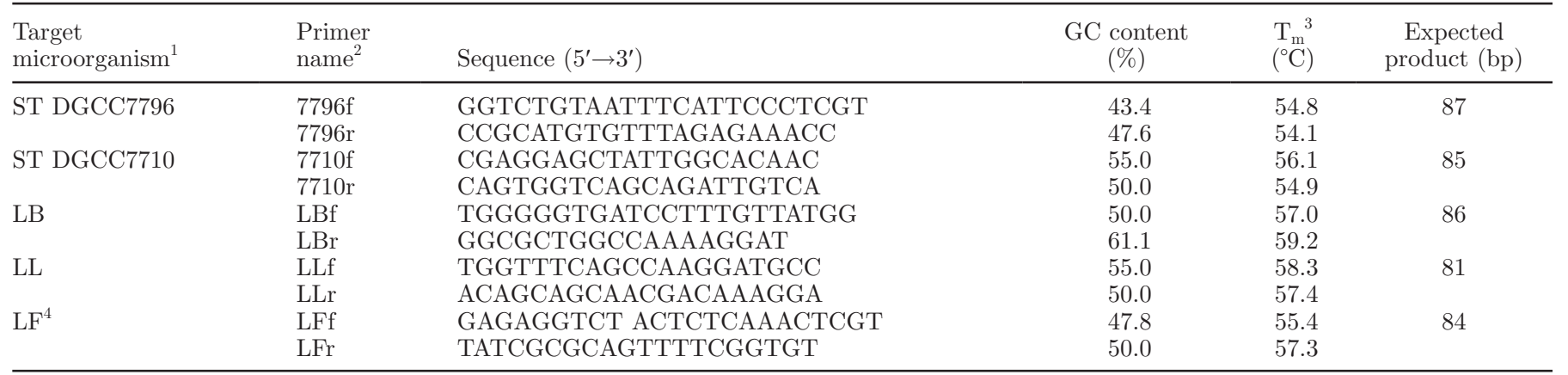

${ }^{1}$ ST DGCC7796 and ST DGCC7710 = Streptococcus thermophilus (ST) strains; LB = Lactobacillus delbrueckii ssp. bulgaricus; LL $=$ Lactobacillus delbrueckii ssp. lactis.

${ }^{2} \mathrm{f}=$ forward primer; $\mathrm{r}=$ reverse primer.

${ }^{3}$ Melting temperature.

${ }^{4}$ This strain was used as an external control and was not part of the commercial starter culture. 
Table 2. Standard curve data for individual starter culture strains spiked in bulk starter base

\begin{tabular}{|c|c|c|c|c|c|c|}
\hline $\begin{array}{l}\text { Target } \\
\text { microorganism }{ }^{1}\end{array}$ & Equation for line ${ }^{2}$ & $\begin{array}{c}\text { Efficiency }^{3} \\
(\%)\end{array}$ & $\mathrm{R}^{2}$ value $^{4}$ & \multicolumn{3}{|c|}{$\mathrm{CI}^{5}$} \\
\hline \multirow{3}{*}{ ST DGCC7796 } & & & & 6.0 & 5.6 & 6.4 \\
\hline & & & & 7.0 & 6.7 & 7.3 \\
\hline & & & & 8.0 & 7.7 & 8.3 \\
\hline ST DGCC7710 & & & & 8.0 & 7.6 & 8.2 \\
\hline \multirow[t]{4}{*}{ LB } & $=15.8-0.320$ mean $\mathrm{Ct}$ & 118 & 0.86 & 5.0 & 4.8 & 5.8 \\
\hline & & & & 6.0 & 5.7 & 6.4 \\
\hline & & & & 7.0 & 6.5 & 7.2 \\
\hline & & & & 8.0 & 7.1 & 8.2 \\
\hline LL & $=14.5-0.277$ mean $\mathrm{Ct}$ & 98.4 & 0.94 & 5.0 & 4.8 & 5.6 \\
\hline
\end{tabular}

${ }^{1}$ ST DGCC7796 and ST DGCC7710 = Streptococcus thermophilus (ST) strains; LB = Lactobacillus delbrueckii ssp. bulgaricus; LL = Lactobacillus delbrueckii ssp. lactis.

${ }^{2}$ Standard curves relating cycle threshold (Ct) to cell counts (cfu/g) were determined using Minitab 16 software (Minitab Inc., State College, PA). Results are based on combined data for 3 replicates.

${ }^{3}$ The efficiency of PCR reactions was calculated as the average of 3 replicates.

${ }^{4}$ Results are based on combined data for 3 replicates.

${ }^{5}$ Confidence intervals were based on $\alpha=0.05$. Confidence intervals provide the range for counts obtained using the standard curves relating Ct to cell counts (cfu/g).

with lactose (BD) and incubated at $37^{\circ} \mathrm{C}$ for $48 \mathrm{~h}$ (IDF, 1988). Serial dilutions of LB and LL strains were plated in duplicate on acidified MRS agar (BD) and incubated anaerobically at $37^{\circ} \mathrm{C}$ for $72 \mathrm{~h}$ (IDF, 1988). Serial dilutions were used to inoculate prewarmed yogurt mix $\left(41^{\circ} \mathrm{C}\right)$ at concentrations ranging from $10^{5}$ to $10^{8} \mathrm{cfu} / \mathrm{g}$. Prior to DNA extraction, 1:10 dilutions were prepared using $0.1 \%$ Polypeptone. Aliquots $(1 \mathrm{~mL})$ were transferred to sterile, screw-cap microcentrifuge tubes (Sorensen Bioscience Inc., West Salt Lake City, UT) and centrifuged for $5 \mathrm{~min}$ at $16,000 \times g$ to pellet the cells. The supernatant was discarded, and genomic DNA was isolated from the cells with the PowerFood Microbial DNA Isolation Kit (MO BIO Laboratories Inc., Carlsbad, CA) using the manufacturer's procedure for difficult-to-lyse cells, which includes heat treatment at $70^{\circ} \mathrm{C}$ for $10 \mathrm{~min}$. Isolated genomic DNA $(2 \mu \mathrm{L})$ was added to the qPCR reaction mix, and qPCR was conducted as described above. Results were analyzed using iQ5 Optical System Software (version 2.0; Bio-Rad Laboratories Inc.). This experiment was conducted in triplicate.

Regression calculations and confidence intervals (95\%) were determined using Minitab 16 software (Minitab Inc., State College, PA). Statistical analysis of the standard curves was conducted with ANOVA (general linear model). Primer efficiency (E) was calcu- lated using the following equation: $\mathrm{E}=10^{(-1 / \text { slope })}-1$ (Kubista et al., 2006).

Data for combined replicates of individual starter culture strains spiked in yogurt mix are presented in Table 2. Coefficient of determination values of plots of mean cycle threshold $(\mathbf{C t})$ versus $\log \mathrm{cfu} / \mathrm{g}$ for individual replicates ranged from 0.96 to 1.0 , and plots of combined data yielded lower values (0.86 to 0.94 ; Table 2). Efficiencies for combined data ranged from 93.3 (ST DGCC7710) to $118 \%$ (LB).

To simulate yogurt manufacture, which involves multiple strains, standard curves prepared with combinations of the starter culture strains spiked in yogurt mix were determined. For standard curves with strains spiked in yogurt mix, each strain (target) was added at concentrations ranging from approximately $10^{4}$ to $10^{8} \mathrm{cfu} / \mathrm{g}$ along with the other 3 starter culture strains (nontarget), each present at a concentration of approximately $10^{6} \mathrm{cfu} / \mathrm{g}$. Cell counts and $\mathrm{qPCR}$ analysis were conducted as described above. Three replicates of the experiment were performed. For all of the strains, no significant difference $(\alpha<0.05)$ was observed in the slopes of standard curves prepared with individual strains and 4-strain combinations spiked in yogurt mix.

An external control was used to monitor the DNA extraction process and $\mathrm{qPCR}$. Criteria for the external control included an organism that is not commonly 

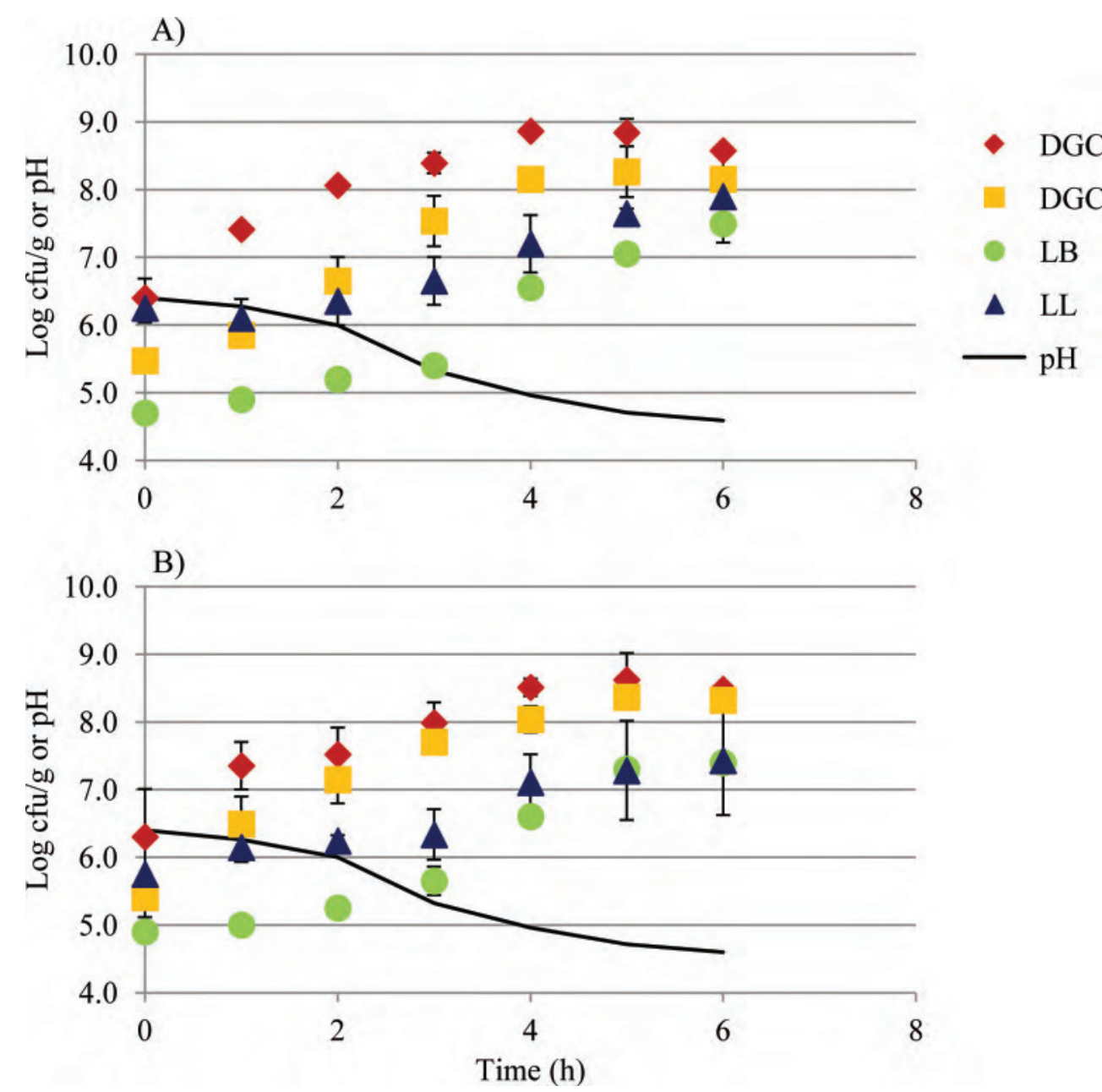

Figure 1. pH data and quantification of individual strains in commercial starter culture (Danisco USA Inc., Madison, WI) inoculated in bulk starter base and incubated at (A) $41^{\circ} \mathrm{C}$ and (B) $43^{\circ} \mathrm{C}$. DGCC7796 and DGCC7710 = Streptococcus thermophilus strains; LB = Lactobacillus delbrueckii ssp. bulgaricus; LL = Lactobacillus delbrueckii ssp. lactis. Color version available in the online PDF.

present in a dairy processing environment and would exhibit similar lysis characteristics as the starter culture strains. Lactobacillus farciminis ATCC $29644^{\mathrm{T}}$ (LF; American Type Strain Culture Collection, Manassas, VA) was selected, as this microorganism possesses a similar peptidoglycan structure (Lys-D-Asp) as LB and LL (Reuter, 1983; Schillinger and Lücke, 1987; Settanni et al., 2005; Felis and Dellaglio, 2007), and is more commonly associated with marinated meats and sourdough bread. A primer set targeting LF 16S-23S rDNA ITS (accession number AF500490) was designed using Primer-Blast (Table 1; Rachman et al., 2003). Specificity was evaluated in silico and by $\mathrm{qPCR}$ using isolated genomic DNA (25 ng/25- $\mu \mathrm{L}$ reaction) from $\mathrm{LF}$ and the 4 starter culture strains. No cross-reactivity was observed with the LF primers and the starter culture strains or the starter culture-specific primers and LF.
For the external control stock, an overnight culture in acidified MRS broth was enumerated by plating and the broth was aliquoted in sterile screw-cap vials and stored at $-80^{\circ} \mathrm{C}$. To determine the mean $\mathrm{Ct}$ and standard deviation for the external control stock, stock was thawed on ice, aliquots $(0.1 \mathrm{~mL})$ were added to diluted yogurt mix (1:10 dilution) immediately before DNA isolation, and $\mathrm{Ct}$ values were determined by qPCR.

When used as the external control, stock from a previously frozen vial was thawed on ice and vortexed thoroughly. A $0.1-\mathrm{mL}$ aliquot was added to $1 \mathrm{~mL}$ of a 1:10 dilution of yogurt mix that had been pregrown with LB and ST immediately before DNA isolation. After qPCR, Ct values from the quantification of $\mathrm{LF}$ spiked into yogurt samples were compared with the mean Ct value previously determined for the external control stock prepared in MRS broth. If these $\mathrm{Ct}$ values 
differed by greater than 3 standard deviations, DNA isolation and $\mathrm{qPCR}$ would be repeated using a backup sample. However, the DNA extraction process used in this work was highly reproducible.

To demonstrate the application of the qPCR method for following strain balance, we monitored growth of 2 ST strains, 1 LB strain, and 1 LL strain during yogurt manufacture at 2 different temperatures. Yogurt mix inoculated with the freeze-dried commercial starter culture (50 g, Danisco USA Inc.) was dispensed into 2 sterile bottles and incubated at 41 and $43^{\circ} \mathrm{C}$ until pH 4.6 was reached. Samples for $\mathrm{qPCR}$ were collected at 1-h intervals. Deoxyribonucleic acid was isolated and qPCR analysis was conducted as previously described. Standard curves were used to relate $\mathrm{Ct}$ values to cell counts. Two replicates of the experiment were performed.

Estimated counts of the 4 strains are presented in Figure 1. At both 41 and $43^{\circ} \mathrm{C}$, ST DGCC7796 was the predominant strain, followed by ST DGCC7710. Acidification profiles were similar at both temperatures. Whereas conventional plating methods do not allow for quantification of individual ST strains, this method provided a useful way of following strain dynamics under different growth conditions. The method described here suggests that CRISPR sequences may contain sufficient variation to permit rapid development of a specific assay for strains where limited genomic information is available. We will apply this method in the future to study the influence of different formulations and processing conditions on yogurt strain balance, and to develop assays targeting other strains of ST, LB, and LL.

\section{ACKNOWLEDGMENTS}

We thank Roldolphe Barrangou (Danisco DuPont, Madison, WI) for providing the strains used in this work and for information on strain-specific CRISPR sequences.

\section{REFERENCES}

Auclair, J., and J. P. Accolas. 1983. Use of thermophilic lactic starters in the dairy industry. Antonie van Leeuwenhoek 49:313-326.

Barrangou, R., C. Fremaux, H. Deveau, M. Richards, P. Boyaval, S. Moineau, D. A. Romero, and P. Horvath. 2007. CRISPR provides acquired resistance against viruses in prokaryotes. Science 315:1709-1712.

Broadbent, J. R., D. J. McMahon, D. L. Welker, C. J. Oberg, and S. Moineau. 2003. Biochemistry, genetics, and applications of exopolysaccharide production in Streptococcus thermophilus: A review. J. Dairy Sci. 86:407-423.

Chandan, R. C., and K. R. O'Rell. 2006. Principles of yogurt processing. Pages 195-209 in Manufacturing Yogurt and Fermented Milks. Blackwell Publishing, Ames, IA.

Felis, G. E., and F. Dellaglio. 2007. Taxonomy of Lactobacilli and Bifidobacteria. Curr. Issues Intest. Microbiol. 8:44-61.

Horvath, P., A.-C. Coûté-Monvoisin, D. A. Romero, P. Boyaval, C. Fremaux, and R. Barrangou. 2009. Comparative analysis of CRISPR loci in lactic acid bacteria genomes. Int. J. Food Microbiol. 131:62-70.

Horvath, P., D. A. Romero, A.-C. Coûté-Monvoisin, M. Richards, H. Deveau, S. Moineau, P. Boyaval, C. Fremaux, and R. Barrangou. 2008. Diversity, activity, and evolution of CRISPR loci in Streptococcus thermophilus. J. Bacteriol. 190:1401-1412.

Imhof, R., H. Glättli, and J. O. Bosset. 1995. Volatile organic compounds produced by thermophilic and mesophilic single strain dairy starter cultures. LWT-Food Sci. and Technol. 28:78-86.

IDF (International Dairy Federation). 1988. Yogurt-Enumeration of characteristic microorganisms - Colony count technique at $37^{\circ} \mathrm{C}$. IDF 117A:1988. IDF, Brussels, Belgium.

Kubista, M., J. M. Andrade, M. Bengtsson, A. Forootan, J. Jonák, K. Lind, R. Sindelka, R. Sjöback, B. Sjögreen, L. Strömbom, A. Ståhlberg, and N. Zoric. 2006. The real-time polymerase chain reaction. Mol. Aspects Med. 27:95-125.

Rachman, C. N., P. Kabadjova, H. Prévost, and X. Dousset. 2003. Identification of Lactobacillus alimentarius and Lactobacillus farciminis with 16S-23S rDNA intergenic spacer region polymorphism and PCR amplification using species-specific oligonucleotide. J. Appl. Microbiol. 95:1207-1216.

Radke-Mitchell, L. C., and W. E. Sandine. 1986. Influence of temperature on associative growth of Streptococcus thermophilus and Lactobacillus bulgaricus. J. Dairy Sci. 69:2558-2568.

Reuter, G. 1983. Lactobacillus alimentarius sp. nov., nom. rev. and Lactobacillus farciminis sp. nov., nom. rev. Syst. Appl. Microbiol. 4:277-279

Schillinger, U., and F.-K. Lücke. 1987. Identification of lactobacilli from meat and meat products. Food Microbiol. 4:199-208.

Settanni, L., D. van Sinderen, J. Rossi, and A. Corsetti. 2005. Rapid differentiation and in situ detection of 16 sourdough Lactobacillus species by multiplex PCR. Appl. Environ. Microbiol. 71:30493059

Tamime, A. Y., and R. K. Robinson. 1999. Biochemistry of fermentation. Pages 432-485 in Yoghurt Science and Technology. 2nd ed. Woodhead Publishing Ltd., Cambridge, UK. 